\section{Human-Animal Medicine: Clinical Approaches to Zoonoses, Toxicants and Other Shared Health Risks}

\author{
Peter M. Rabinowitz \\ and Lisa A. Conti
}

Saunders, Maryland Heights, MD, USA, 2009

ISBN: 10-1416068376

Pages: 432; Price: US \$99.95

Hooray, finally a book emerges about the human-animal interface that addresses both perspectives equitably and seamlessly. Peter Rabinowitz, a physician, and Lisa Conti, a veterinarian, effectively present material that is thorough, balanced, and of great relevance for practitioners of all varieties of medicine.

More than half the pages comprise reports on each of 35 zoonoses. At the beginning of each report are key points divided into professional categories - public health professionals, human health clinicians, and veterinary clinicians - ensuring relevance for multiple readers. In addition, 55 pages deal with toxicoses, including environmental, gaseous, poisonous plants, herbicides/pesticides, and envenomations. Clinical signs, symptoms, species comparisons, treatment and prevention for these toxicoses are all spelled out clearly.

This inclusive approach, with its plentiful and accurate technical information, might be enough to justify purchasing the book for the shelf of any human or veterinary medical practice, but it is the additional 175 pages that set this volume apart from all others on the subject. A lengthy introductory chapter discusses the general concept of one medicine and why that concept does not mean one practitioner but rather integration of practitioners from multiple sectors. The chapter describes the serious legal and ethical considerations associated with professionally crossing the human-animal interface. The occupational health of animal workers is covered in detail and includes not only zoonotic agents that immediately come to mind, but also allergens, use of live vaccines, noise, anesthetic gases, and the psychosocial impacts of such issues as euthanasia. Animalassisted therapy is covered in detail. The book includes a particularly useful section on immunocompromised persons and their exposure to animals and another one on animal bites. There is even a segment on travel, including concerns about wild animal contact, as well as disease hazards for pets that travel. These additional chapters make parts of this book relevant for a much wider audience that could potentially include policy makers, regulators, students, and academicians.

Throughout, the book is graphically pleasing, with text broken regularly by subheadings, tables, pen-and-ink drawings, algorithms, photographs, and intriguing side bars. Some of the side bars are case studies, with interesting scenarios and quick tips for promoting health.

\section{Corrie Brown}

Author affiliation: University of Georgia, Athens, Georgia, USA

\section{DOI: 10.3201/eid1606.100367}

Address for correspondence: Corrie Brown, College of Veterinary Medicine, D.W. Brooks Dr, University of Georgia, Athens, GA $30602-$ 7388, USA; email: corbrown@uga.edu

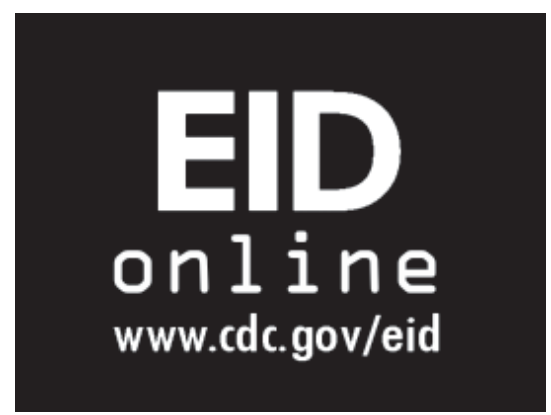

\section{Who's in Charge? \\ Leadership during Epidemics, Bioterror Attacks, and Other Public Health Crises}

\author{
Laura H. Kahn
}

Praeger Security International,

Santa Barbara, CA, USA, 2009

ISBN 978-0275994853

Pages: 236; Price: US \$49.95

Dr Laura Kahn has produced a useful book that provides a brief historical background on public health and terrorism, followed by interesting examples of leadership during outbreaks and events that escalated to public health crises. The roles of astute clinicians, public health professionals, appointed public health leaders, and elected officials are described by the players themselves. These insights provide important perspectives and are fascinating reading, but each event includes the voices of only a few of many participants. This omission may leave the reader hungry for a wider variety of viewpoints.

Kahn takes the reader through a thought-provoking overview of the complexity of leadership and some early milestones in public health. Kahn makes it clear that politics, economics, communications, and interpersonal relations are as central to today's public health crises as they were in the past.

Persuasive examples support Kahn's main thesis that political leadership is critical during a public health crisis, whether the crisis results from natural causes or from bioterrorism. Kahn says, "Questions about leaders and leadership have intrigued scholars in both Western and Eastern civilizations for centuries. Plato, Confucius, and Machiavelli all speculated about leaders... and the qualities of leadership." Kahn concludes that 1) informed, engaged, and prepared elected officials are essential to effective 
response; 2) because crisis response decisions inevitably will be made in the absence of perfect information, leaders require judgment and common sense; 3) elected and appointed leaders must be effective; and 4) dual leadership during a crisis can cause confusion.

The author provides a convincing case for her conclusions with lively examples and first-hand accounts and offers several concrete suggestions to prepare elected officials for leadership roles. The same compelling case is not made for Kahn's assertion of a "legal conundrum when dealing with the bioterrorism attack." She suggests that the Centers for Disease Control and Prevention (CDC) should lead the public health response to such episodes but alleges that legal and organizational impediments hinder CDC from fulfilling that lead role.

Unquestionably, CDC must and does play a lead role during largescale, multistate public health events. The legal and organizational impediments to fulfilling that role are not ob- vious to this reviewer, especially given CDC's success in addressing many such crises. Kahn may be referring to impediments within the federal structure and chain of command. However, current law specifies the roles of CDC and the departments of Health and $\mathrm{Hu}-$ man Services, and Homeland Security. CDC has ample legal authority to supplement its technical and scientific leadership during an emergency, especially when state and local capacities are outstripped.

Kahn suggests federalizing and centralizing the national response system through changes in the legal framework and organizational structures of the public health system, arguing that if CDC were organized for response as the Environmental Protection Agency or the Federal Bureau of Investigation is, delays, leadership confusion, and communication issues would be resolved. She identifies some leadership problems but fails to acknowledge the strong collegial relationship between state public health authorities and CDC that has produced innumerable successful responses to crises. Restructuring the traditional relationship between states and the federal government seems unnecessary.

This problem does not overshadow an otherwise informative and engrossing book. In an era of emerging infectious diseases, bioterrorism, and large-scale natural disasters, we will continue to have to address the types of events Dr. Kahn describes. Those involved in responding to such events would benefit from studying the lessons of the past to better manage future emergencies.

\section{Patrick J. McConnon}

Author affiliation: Council of State and Territorial Epidemiologists, Atlanta, Georgia, USA

\section{DOI: 10.3201/eid1606.100345}

Address for correspondence: Patrick J. McConnon, Council of State and Territorial Epidemiologists, 2872 Woodcock Blvd, Suite 303, Atlanta, GA 30341, USA; email: pmcconnon@cste.org

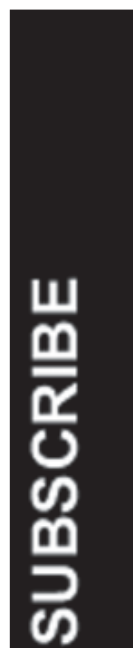

EMERGING INFECTIOUS DISEASES ${ }^{\circ}$

$\square$ YES, I would like to receive Emerging Infectious Diseases. Please add me to your mailing list.

Return:

Email: eideditor@cdc.gov

Fax: 404 639-1954

Mail to:

EID Editor

$\mathrm{CDC} / \mathrm{NCID} / \mathrm{MS}$ D61

1600 Clifton Rd, NE Atlanta, GA 30333
Number on mailing label:(required)

Name:

Full mailing address: (BLOCK LETTERS)

Full text free online at www.cdc.gov/eid 